\title{
The Scope of Perceptual Knowledge
}

\author{
ALAN MILLAR
}

Seeing, hearing, feeling, smelling or tasting that something is so, are all forms of sense-perceptual knowledge (which, hereafter, I call simply perceptual knowledge). I shall be concerned with perceptual knowledge in its primary sense on which it satisfies the following perceived-object condition: If you perceive that $A$ is an $F$ (or is $G$ ) then you perceive $A$. T here are conceptions of perceptual knowledge on which this condition is not met. D retske, for example, has suggested that there is a sense of 'seeing that' on which a traffic officer may see that a driver was exceeding the speed limit by seeing that tyre marks, produced by sudden braking action, are of a certain length. Though in this sense the officer sees that the driver was exceeding the limit, he need not see the driver. ${ }^{1}$ I shall not take issue with this way of thinking. G ranted that the knowledge illustrated by $D$ retske's example is, in some sense, perceptual, it clearly depends on perceptual knowledge which satisfies the perceived-object condition. D retske's traffic officer relies on knowing that the tyre marks, which he sees, are of a certain length.

Even with the restriction to perceptual knowledge in the primary sense there is a substantive issue concerning the scope of perceptual knowledge. A plausible way of conceiving of such knowledge treats it as satisfying at least the following conditions:

1) It is knowledge about things from the way they appear, that is, from the way they look, sound, feel, smell or taste. So, if we can know visually that something is, say, a bottle of milk, then that knowledge is knowledge from the way the thing looks.

(2) It can embrace more than facts pertaining only to the way things appear. Surely we might know visually that something is a bottle of milk from the way it looks. If so then our knowledge embraces more than knowledge merely of the way the object in question looks, since the fact that something is a bottle of milk is not a fact merely about the way the thing looks.

(3) It is phenomenologically immediate, in the sense that it is not acquired via inference from prior assumptions. If you know

${ }^{1}$ Fred $D$ retske, S eeing and $K$ nowing ( $L$ ondon: R outledge and $K$ egan Paul, 1969), 153. 


\section{Alan Millar}

perceptually that something is a bottle of milk then it simply strikes you that this is so on seeing it. You do not infer that it is so from an assumption to the effect that it looks a certain way. In this context inference is reasoning on the subject's part. ${ }^{2}$

I accept each of these assumptions. What interests me is the fact that (2) and (3) place a significant constraint on adequate elucidations of (1). (2) allows us to count the knowledge that the object is a bottle of milk as perceptual, despite its embracing more than the way the object looks, but granted (3) this knowledge had better not turn out to be inferential.

Crucial to the perspective I wish to defend is a distinction between facts which we know perceptually and facts which are, strictly speaking, perceptually manifest to us. Perceptually manifest facts concern only the way things appear, but, in line with (2), perceptual knowledge can embrace more than the perceptually manifest. One of my main aims is to elucidate (1) in a manner which is consistent with (2) and (3). I want to steer a course between two conflicting tendencies which remain influential in philosophical thinking about perceptual knowledge. One of these is associated with empiricism in its classic forms. It happily recognizes a strict conception of the perceptually manifest, limits perceptual knowledge to facts which are perceptually manifest in this strict sense, and treats facts as to how things appear as evidence from which judgements which go beyond what is perceptually manifest must be inferred. For ease of reference I shall call this, without qualification, the empiricist view, though I recognize that there are forms of empiricism which are less austere. The other tendency is more liberal and has been prominent in recent philosophy. It holds that perceptual knowledge that $p$ is any knowledge that $p$ which arises immediately from current perception, that is, without inference from prior assumptions. I shall call this the non-inferentialist view. $\mathrm{N}$ ote that this view does more than endorse (3). (3) states only that if knowledge is perceptual then it is phenomenologically immediate and arises from perception. T he non-inferentialist view entails that if knowledge is phenomenologically immediate and arises out of perception then it is perceptual knowledge. This view is certainly more liberal than the empiricist view, because it allows us to know more perceptually than facts which are perceptually manifest in the

${ }^{2}$ I take it that reasoning occurs both when one considers premises and draws conclusions from them, but also when one makes a transition unreflectively from a set of beliefs to some other belief. I emphasise that reasoning is on the subject's part since inference in the intended sense is something people do and not something which their sub-personal cognitive systems do. 
strict sense which is tied to appearances. As we shall see presently, it is also more liberal than the view which I favour.

T he non-inferentialist view crops up in discussions of a remarkably broad range of topics. $\mathrm{H}$ ere is a passage dealing with observation $^{3}$ in science from a recent book by R obert Brandom:

[I ]t is important to understand that under the appropriate circumstances, which include the presence of a bubble-chamber or similar device, and for the right community of observers, mumesons are literally observable - non-inferentially reportable in much the same sense in which red things are for the rest of us. It is a mistake to think that what is really, non-inferentially, observed is only the vapour trail and that the presence of mumesons is only inferred. ${ }^{4}$

A similar line was taken much earlier by $\mathrm{G}$ ilbert $\mathrm{H}$ arman in an influential discussion of observation and morality. $\mathrm{H}$ arman takes it that an observation is 'an immediate judgment made in response to the situation without any conscious reasoning having taken place'. ${ }^{5} \mathrm{~L}$ ike Brandom, he counts the scientist who thinks, 'T here goes a proton', on looking at a vapour trail in a cloud chamber as, thereby, making an observation, since the judgment in question is not inferential and is an immediate (perception-prompted) response to the situation. $\mathrm{H}$ arman notes another striking implication. In the absence of any additional refinements, the view implies that there can be moral observations, since judgments as to the rightness or wrongness of some witnessed action can be phenomenologically immediate. Witnessing a vicious assault it may simply strike you that it is wrong. Y ou need not reason that since the action takes a certain form, specified in morally neutral terms, and since actions of that form are wrong, this action is wrong; you just see that it is. Admittedly, it is part of $\mathrm{H}$ arman's aim to make out that there is an important distinction between the role of observation in relation to scientific theory

${ }^{3}$ For the purposes of this paper I shall take observation and perception to amount to the same thing, but I do not wish to exclude the possibility that in some contexts, for example, an analysis of the notion of observation used by scientists, there might be reason to distinguish between them.

${ }^{4}$ Robert Brandon, $M$ aking It Explicit (Cambridge, M A.: H arvard U niversity Press, 1994), 223.

${ }^{5}$ Gilbert $\mathrm{H}$ arman, The $\mathrm{N}$ ature of $\mathrm{M}$ orality ( $\mathrm{N}$ ew York: Oxford U niversity Press, 1977), 6. T he quoted passage leaves room for the possibility that the judgment results from inference which is not conscious. I shall not make anything of this possibility in what follows and so will talk without qualification of judgments or beliefs being inferential or otherwise. I shall take inferential beliefs or judgments to be the termini of transitions from beliefs/judgments to beliefs/judgments. 


\section{Alan Millar}

and its role in relation to bodies of moral principle. $\mathrm{He}$ thinks that whereas an observation in science can confirm a theory, because the theory can better explain the observation's being made than alternatives can, a moral observation cannot confirm a body of moral principles, because such principles cannot explain the observation's being made. For $\mathrm{H}$ arman there are no moral facts to which bodies of principle are answerable, and so no moral knowledge, yet the claim that there are moral observations remains in place and, in any case, is, plausibly, one to which $\mathrm{H}$ arman is committed by adopting the noninferentiality criterion. It is interesting to note that J ohn M CD owell makes use of, what is in effect, a notion of moral observation, in the defence of the possibility of moral knowledge. He writes:

A kind person can be relied on to behave kindly when that is what the situation requires. ... [T ] that the situation requires a certain sort of behaviour is (one way of formulating) his reason for behaving in that way, on each of the relevant occasions. So it must be something of which, on each of the relevant occasions, he is aware. A kind person has a reliable sensitivity to a certain sort of requirement which situations impose on behaviour. T he deliverances of a reliable sensitivity are cases of knowledge; and there are idioms according to which the sensitivity itself can appropriately be described as knowledge: a kind person knows what it is like to be confronted with a requirement of kindness. T he sensitivity is, we might say, a sort of perceptual capacity. ${ }^{6}$

What make sense of the view that the sensitivity in question is a perceptual capacity is the idea that it yields what M CD owell regards as true non-inferential moral judgments in response to witnessed situations.

A unifying theme of $M$ cD owell's work has been that there are kinds of knowledge which philosophers have not generally taken to be perceptual but which, on closer analysis, can be shown to be so. In some of this work the non-inferentialist view is fairly evident, if not exactly explicit. Addressing the 'other minds' problem, M cD owell opposes the view that 'our best warrant for a psychological judgement about another person is defeasible evidence constituted by his "behaviour" and "bodily" circumstances'. ${ }^{7} \mathrm{He}$ favours

${ }^{6}$ John M cD owell, 'Virtue and Reason', T he M onist 62, 1979, 331-2. What seems to be essentially the same view is outlined in $M C D$ owell's M ind and World (Cambridge, M A.: H arvard U niversity Press, 1994). See especially L ecture IV, section 7.

${ }^{7} \mathrm{~J}$ ohn $\mathrm{M}$ cD owell, 'C riteria, D efeasibility and K nowledge', $\mathrm{P}$ roceedings of the B ritish A cademy $\mathbf{6 8}, 1982,455-79$. The quotation occurs on p. 468. 
instead a model on which such facts as that a person is giving expression to his anxiety are, as he puts it, 'directly presented to view' (op. cit., p. 473). Expressing anxiety, in M cD owell's sense, is displaying real anxiety, not merely looking anxious. T he point is that psychological conditions like expressing anxiety are viewed as being among those which can be made perceptually manifest. The non-inferentiality criterion makes sense both of this view and $M c D$ owell's rejection of the evidentialist position. As he sees it, the evidentialist position falsifies the phenomenology; we don't infer that the person is expressing anxiety from some more basic nonpsychological fact; rather, we see that the person is expressing anxiety. T hat makes sense if seeing that $p$ is a matter of telling that $p$, prompted by current perception, and without conscious inference. $M$ CD owell adopts essentially the same approach in discussing our understanding of what people say. I n opposition to the evidentialist stance which he discerns in Dummett's work, he argues that '[c]ommand of a language is partly constituted by ... a perceptual capacity; one whose acquisition makes a new range of facts, not hitherto within one's perceptual ken, available to one's awareness'. ${ }^{8}$

I share with the non-inferentialist a concern to ensure that we do not unduly restrict the scope of observation- of perceptual knowledge. ${ }^{9}$ As already indicated, I think that perceptual knowledge embraces more than facts which are perceptually manifest, that is, facts pertaining only to how things appear. N evertheless I do think that all perceptual knowledge is a response to what is perceptually manifest in this fairly strict sense. One of my aims is to elucidate what it is to know about something from the way it appears in a way which avoids making such knowledge out to be inferential. I am also interested in exploring the relation between the view which emerges and the non-inferentialist view. I t will turn out that the non-inferentialist view is too permissive, but that the view I favour is by no means as illiberal as one might expect. T he next step is to look more closely into the relevant conception of appearances.

\section{II}

T he look, sound, feel, taste and smell of a thing are all appearances of that thing relative to one or other sense. I shall also use locutions

${ }^{8}$ John M CD owell, 'Anti-Realism and the Epistemology of Understanding' in Herman Parret and Jacques Bouvresse (eds) M eaning and U nderstanding (Berlin: Walter de G ruyter, 1981), 225-48. T he quotation occurs on p. 239.

${ }^{9}$ Such a concern is explicitly expressed in $\mathrm{D}$ avid $\mathrm{M} \mathrm{cN}$ aughton, $\mathrm{M}$ oral $V$ ision (Oxford: Blackwell, 1988), 56-7. M cN aughton is strongly influenced by $\mathrm{M} C \mathrm{CD}$ owell. 


\section{Alan Millar}

like 'the way A looks', taking this to mean the same as 'the look of $A^{\prime}$ '. M y initial task in this section is to clarify this way of thinking about appearances. T he key points are these:

(a) W hen I speak of the way some particular apple looks I am not talking about how it strikes some individual who is looking at it, but about a feature of the apple which, like its colour or shape, is objective, in that it is possessed whether or not the apple is being perceived, and publicly available, in that it can be visually discriminated by any suitably equipped subject. ${ }^{10}$ I shall sum up this point by saying that appearances in the sense intended are worldly appearances. ${ }^{11}$ We routinely think of appearances in just this way. If I ask you whether you are familiar with the taste of R iesling, I am enquiring about your familiarity or otherwise with a feature of a certain type of wine, and not about how a sample of wine of that type now tastes to you. Similarly, if I ask you if you are familiar with the look of an old fashioned British red telephone booth, my question is about a feature of such booths irrespective of whether you are actually looking at one. We do, of course, have a notion of how something appears to a subject. T he question might arise how this particular glass of Riesling tastes to you now. It would be a mistake, however, to think that notions of this latter sort are prior in the order of understanding to notions of worldly tastes. Our understanding of what it is for a particular wine to taste a certain way to one now depends on our having notions of worldly tastes, for example, the notion of the taste of a wine when it has a bad cork. And our ability to convey to others how a wine tastes to us now depends on their sharing those notions of worldly tastes with us.

(b) Something has the appearance of an $F$ (of $X /$ being $G$ ) relative to a given sense, if it appears relative to that sense the way an $F$ typically does (the way $X$ typically does/ things which are $G$ typically do). On this understanding a thing can have the look of an apple and not be an apple, or the sound of a sky lark's song and not be a sky lark's song, or the taste of fresh coriander and not be fresh coriander.

${ }^{10} \mathrm{~T}$ his point is compatible with views which make sense of the idea that some objective features, e.g., mass, are more objective than others, e.g., colour.

${ }^{11}$ I n making the notion of worldly appearances basic I differ from the approach of D retske, op. cit., 20ff., F rank J ackson, P erception (C ambridge University Press, 1977), chapter 7, and Roderick Chisholm Perceiving (I thaca, N Y.: Cornell U niversity Press, 1957). T hese authors work with a notion of an object's appearing some way to a subject on a given occasion. 
(c) Although appearances are worldly they are, none the less, perceiver-relative in that they are looks, feels, sounds, tastes and smells, relative to the powers of discrimination of suitably sensitive perceivers. $T$ he tendency in empiricist tradition has been to count all those who have a sense in good working order as suitably sensitive perceivers, with respect to the use of that sense. I $t$ is true that sometimes we are interested in how things look, for example, relative to the powers of discrimination of any perceivers with properly functioning sight. It is clear, however, that an adequate account of worldly appearances must acknowledge appearances which some of those who have the relevant sense in good working order may not be able to discriminate. As I student I received training in discriminating some sixty varieties of potato from the look of their plants. T his put me in a position to make discriminations I could not make prior to the training and could not make now. Relative to those who had the training the look of $\mathrm{K}$ ing $\mathrm{E}$ dwards was very different from the look of Pentland Crown. Similar points obviously apply to the tastes and smells of wines. ${ }^{12}$

(d) A ppearances in the relevant sense are also relative to conditions of observation and points of view. The look of Edinburgh Castle floodlit at night, and seen from Princes Street, is very different from its look from the west in daylight. In what follows I shall not always spell out values for all the relevant parameters relative to which an object appears some way. M any of the points I shall make are schematic points which stand in for a variety of more specific points for which the parameters are fixed in some way.

The view I am concerned to defend is that perceptual knowledge about something is knowledge of that thing from the way it appears relative to some sense. The non-inferentialist view, by contrast, explicates perceptual knowledge in terms of the phenomenological immediacy of perceptual beliefs and judgements. D efenders of the non-inferentialist view tend not to give the notion of appearance any real philosophical work to do, perhaps because they wish to distance themselves from the empiricist view. T hey must, however, be able to make sense of our talk of appearances. It would be in the spirit of the non-inferentialist view to treat facts as to the way things appear as being facts which can be non-inferentially known via perception. Some of M cD owell's remarks are consistent with such a view. On his treatment of the 'other minds' case, the fact that the

${ }^{12}$ It is important not to confuse the claim that appearances are relative in the way acknowledged here with the claim that the notion of the appearance of a thing is to be explained in terms of a prior notion of a thing's appearing some way to some individual. 


\section{Alan Millar}

person is expressing anxiety (in a sense which entails that he is anxious) is treated as a fact as to the way he appears, which can be made manifest to a suitably sensitive perceiver. T he reason $M c D$ owell believes himself to be entitled to think of this fact in this way is that he thinks it is a fact which can be known to obtain non-inferentially, by a suitably sensitive perceiver, on looking at the person in question. I have no quarrel with the idea that such a fact can be noninferentially known in that way. $\mathrm{N}$ evertheless, there is a readily intelligible sense in which, even so, it would not be, strictly speaking, perceptually manifest. On this strict sense a fact is perceptually manifest to a subject only if it is a fact as to how things appear, in the sense I have been explaining. Suppose that in some actual situation it is visually manifest to you that $A$ is $G$. T hen since facts which are visually manifest are facts about the looks of things, there is no possible situation (with all the relevant parameters held constant) in which everything looks just as it does in the actual situation but in which it is false that $A$ is $G$. If there were a possible situation in which it is false that $A$ is $G$ yet everything (including $A$ ) looked the same as in the actual situation, then clearly the fact that $A$ is $G$ would not be a fact merely about the look of $A$. Suppose then that someone is expressing anxiety in some situation (and recall that doing so entails being anxious). Clearly, there is a possible situation in which the person looks just the same, having the demeanour of an anxious person, but is not actually expressing anxiety. So, on this understanding of what is perceptually manifest, it cannot be perceptually manifest to you that the person is expressing anxiety. On the other hand, the fact that a person looks anxious can pass the test because in any situation in which he looked just as he does in the actual situation he would look anxious. ${ }^{13} \mathrm{~N}$ ote that although this conception of what is perceptually manifest is strict, in that it rules out such facts as that a person is expressing anxiety, it is consistent with the view that what is perceptually manifest is relative to perceivers with special sensitivities which not all who have the relevant sense in good working order are bound to possess. W hat we have is a conception of what is perceptually manifest which is narrower than M CD owell's but which, like M CD owell's, allows for individual differences in sensitivity.

${ }^{13}$ Someone might accept the suggested principle for what is perceptual ly manifest, but argue that any situation in which a person does not express anxiety would not be one in which everything appeared as it does in the situation in which the person does express anxiety. I doubt that this corresponds to how we actually think of appearances. I n any case, it is not a notion of appearances on which appearances are looks, feels, sounds etc. For clearly the look of our subject could remain constant across two situations in only one of which the person is expressing anxiety. 
Analogous considerations apply to other examples we have touched upon. Suppose someone in your presence says, 'I t's raining' in just these words. You believe that she said that it's raining. $T$ he belief is not acquired by way of inference from prior assumptions. Even so, we can imagine a counterpart situation in which everything sounded as it did in the actual situation but in which the speaker does not say that it is raining. Suppose, for example, that in the counterpart situation the speaker does not speak English at all, but sounds as if she did. I magine that she has picked up the words in the conversation of others, utters them, for a laugh, while skilfully making them seem just like a move in English conversation. I take it that such a person would not count as saying that it's raining. Yet nothing concerning the way things sound need be different from the actual situation in which the speaker does say that it is raining. T hat makes sense of the idea that it was not audibly manifest that the speaker in the actual situation said that it was raining. ${ }^{14}$

So far I have been concerned with the distinction between facts which are and facts which are not perceptually manifest. A nalogous considerations can be applied to the distinction between objects which are and objects which are not perceptually manifest. I n keeping with the spirit of the discussion so far, the relevant test for whether or not an object is visually manifest in some situation is this: I $f$ it is visually manifest, then there is no possible situation in which things look exactly as they do in this situation but in which the object is not present. L et us apply this to the case of the subatomic particle. I do not myself think that the sub-atomic particle in the cloud chamber is seen. ${ }^{15}$ I ntuitively, it is not seen because it does not look any way. This might be challenged on the grounds that particles passing through cloud chambers have the look of the front end of a vapour trail. (W ell, somebody might think so.) But by

${ }^{14}$ I really do want to stress that there is no assumption here that the way things sound concerns only sounds heard as meaningless. R ecall the earlier point that suitable sensitivities may involve special skills. M CD owell is right to insist, as he frequently does, that it does not count against the claim that some fact is 'directly presented to view' that it can be so presented only to people who have a perceptual ability which perceivers in general are not bound to have.

${ }^{15}$ In this I am with Bas van Frassen The Scientific I mage (Oxford: Clarendon Press, 1985). See, especially, p. 17. D retske has a characteristically subtle and insightful line on this example drawing upon his conception of secondary epistemic perception (op. cit., chapter VI). He allows that there can be perceptual knowledge about the particle, but this species of perceptual knowledge does not satisfy the perceived-object condition. $D$ retske, unlike Brandom in the passage quoted earlier, does not think that the particle is perceived and nor do I. 


\section{Alan Millar}

the test for an object's being visually manifest, this is not so since there is a possible situation in which there is a vapour trail, but no sub-atomic particle passing through. I t is a contingent fact, after all, that the vapour trail is caused by the passage of a particle. W hat is seen (bearing in mind that we are dealing with perception in the primary sense) must not only affect the way things look in a situation, it must itself look some way. This particle affects the way things look but does not itself look any way.

I have now clarified the conception of appearances, which figures in my view of perceptual knowledge, and introduced a strict conception of what is perceptually manifest in terms of that conception. D efenders of the non-inferentialist view may suggest, for example, that when we say that we know that the person is expressing anxiety from the way he looks, we are not explaining how we know in terms of a fact which, as M CD owell puts it, falls short of the fact that the person is expressing anxiety. (See M cD owell, op. cit., 472.) T he idea would be that knowing that he is expressing anxiety from the way he looks is just taking in visually (that is, here, non-inferentially, in response to looking) the fact that the person is expressing anxiety. I find this unsatisfactory because even if we concede, as I do, that the fact that the person is expressing anxiety can be visually known, it seems to me that it can hardly be denied that an explanation of how this fact can be visually known ought to allude to a fact which is visually manifest in the strict sense- a fact, to the effect that the person looks anxious, which could obtain even if the person were not anxious, and thus not expressing anxiety. ${ }^{16} \mathrm{~T}$ his might seem to beg the question against the non-inferentialist. $M$ y aim, however, is not so much to

${ }^{16} \mathrm{M}$ CD owell, in 'C riteria, D efeasibility, and K nowledge' 472f., works with the locution 'It appears to $A$ that $p$ ' and proposes that statements to this effect have a disjunctive analysis. They are true if either it merely appears that $p$ or if the fact that $p$ makes itself perceptually manifest to $A$. T he trick is that it can be true that it appears to $A$ that $p$ both in a situation in which $p$ and in a situation in which not-p, but we are not to suppose that there is a psychological state, describable as its appearing to one that $p$ which is common to two such situations. I have argued, in 'T he I dea of Experience', Proceedings of the A ristotelian Society 97, 1996, 75-90, that this view is not well motivated, though I think it is possible to make sense of why one might wish to avoid positing a psychological state which is common to the situation in which $p$ and its deceptive counterpart. As stressed previously the appearances I have been concerned with here are worldly appearances. With respect to these the pressures which seem to call for a disjunctive account of experiences just do not apply. I n any case I find it hard to take seriously the denial that there is a fact common to two situations in one of which a person expresses anxiety and in the other of which the person merely looks anxious. 


\section{The Scope of Perceptual Knowledge}

refute his view, but to show how we can accommodate the prima facie plausible view that knowing that a person is expressing anxiety from the way he looks is in some manner responsive to the visually manifest fact that the person (merely) looks anxious, while acknowledging, with the non-inferentialist, that such knowledge is indeed non-inferential.

\section{III}

We can know by sight that something we are looking at is an apple, though the fact that the thing is an apple is not visually manifest in the strict sense. G iven my concession to the non-inferentialist, it is not open to me to explain what it is to tell that something is an apple from the way it looks in terms of coming to a conclusion that it is an apple from a prior assumption as to how it looks. Before outlining my own view, I want to consider first a proposal which meets this constraint, but which is open to objection. The proposal is suggested by a passage from a recent discussion by D retske which is obviously germane to our current concerns:

We see, by her expression, that she is nervous. She tells that the fabric is silk (not polyester) by the characteristic 'greasy' feel of the fabric itself .... . Perceptual knowledge of this sort is ... derived-derived from the more basic facts ... we use to make the identification. ... D erived knowledge is sometimes described as inferential but this is misleading. At the conscious level there is no passage of the mind from premise to conclusion, no reasoning, no problem-solving. ... The resulting knowledge, though logically derivative, is psychologically immediate. ... I t is this psychological immediacy that makes indirect perceptual knowledge a species of perceptual knowledge. ${ }^{17}$

In this passage D retske speaks of the non-inferential knowledge under discussion as being derived from the facts. T he surrounding context makes it explicit that he thinks that when knowledge that a is $\mathrm{G}$ derives from the fact that $\mathrm{a}$ is $\mathrm{H}$ the subject must know that a is $\mathrm{H}$. An implication of the view is that if you know that something is an apple from the way it looks, then your knowledge depends on your knowing, and thus believing, some fact as to the way the apple

${ }^{17}$ This is from D retske's entry 'perceptual knowledge' in Jonathan Dancy and Ernest Sosa (eds), A Companion to Epistemology (Oxford: Blackwell, 1992). Essentially the same point is made on pp. 158-9 of $D$ retske's $S$ eeing and $\mathrm{K}$ nowing. 


\section{Alan Millar}

looks. ${ }^{18} \mathrm{D}$ retske seems to me quite right in thinking that the claim that knowing that the thing is an apple is dependent in this way does not entail that it is inferential. Still, as it stands the proposal does not tell us how the derived knowledge is dependent upon the knowledge as to how the thing looks. G ranted that it does not come about by way of inference, considered as a psychological process, we still need some account of how it depends on the more basic knowledge. It is not too difficult to supply what is needed in keeping with D retske's picture. I n perception we form, without engaging in any inferential process, ${ }^{19}$ a mass of beliefs relating to our perceived surroundings. $L$ et us call them perception-induced non-inferential beliefs. Despite being non-inferential, such beliefs can be causally dependent on other beliefs, including other beliefs acquired in the same way and at the same time. T hus it may be that you believe on entering a room that a particular individual, Sam, is present. Such a belief might be a perception-induced non-inferential belief, and yet be dependent on your believing that someone who has the look of Sam is present. The latter belief might contribute to sustaining the former so that, if you ceased to hold that someone who has the look of Sam is present, then you might well cease to believe that Sam is present, and, if you were faced with considerations suggesting that it is not Sam who is present, any tendency you might acquire to abandon the belief that he is would have to reckon with your believing that someone who has the look of Sam is present.

U nderpinning this approach is the recognition that even though a belief is non-inferential in the psychological sense-it has not in fact come about by a chain of reasoning-it may none the less causally depend on other beliefs in a manner which makes it appropriate to regard it as being sustained, and thus in a sense based on, those other beliefs. T his gives us a way of developing the idea that when you know perceptually that something is an apple, you know this from the way the apple looks. I t is no objection to this proposal that we do not routinely think to ourselves that the things we perceive have this or that appearance. $\mathrm{M}$ uch of what we believe in immediate response to perception is not in the form of thinkingsto-ourselves. $\mathrm{N}$ or is anything awry about the idea that beliefs acquired non-inferentially can be dependent on other beliefs in the

${ }^{18}$ A similar view is expressed in William P. Alston, 'Concepts of Epistemic Justification' in his Epistemic J ustification (I thaca: Cornell U niversity Press, 1989), 81-114. See especially, p. 99.

${ }_{19}$ Recall that inference here is inference at the personal level, not inference-like processes which may be going on in sub-personal cognitive systems. 
way explained. But despite its attractions, the proposal is open to an objection which, even if not decisive, is powerful enough to motivate a search for a better account. T he objection is that, on the face of it, someone might have the capacity for visual perceptual knowledge that an apple is there, without having the conceptual resources for forming beliefs pertaining to the look of apples. Empiricism in its classic forms, does not entertain such a possibility because it assumes that concepts relating to appearances are bound to be acquired earlier than sortal concepts, like those of familiar fruits and vegetables. But whatever empiricists may have thought, there is no good reason to rule out a priori the possibility that one could have a grasp of sortal concepts, without having acquired concepts pertaining to appearances. I $\mathrm{n}$ fact it is actually rather plausible that someone might learn to discriminate apples by sight without having acquired any concept of the look of an apple. And there are psychologists who hold that the concepts we acquire first are not concepts of features of objects, but sortal concepts of objects which share a certain appearance. ${ }^{20}$ So let us take a different tack.

We are looking for an account of what it is to tell that something is an apple from the way it looks. T he problem with the previous proposal was that it assumed that this involved knowing, and thus believing, that the thing has the look of an apple. But a different account is available which invokes the notion of a discriminative capacity. A creature can be said to discriminate $F \mathrm{~s}$ by sense $M$ when it has the capacity to respond in a distinctive way to $\mathrm{F} s$ which it perceives via M. An example is the trained pigeon's capacity to discriminate photographic slides of trees from photographic slides which are not of trees. ${ }^{21} \mathrm{~T}$ he capacity might consist in a capacity to respond to visually perceived slides of a tree by pecking a device which released food. T he important point is that a capacity to discriminate $\mathrm{F}$ s is not necessarily a capacity to bring $\mathrm{F}$ s under the concept of an F. Although the pigeon discriminates slides of trees, this is not a matter of its bringing slides of trees under the concept of a slide of a tree. Concepts, in the sense intended here, are employed

${ }^{20}$ I have in mind the work of Eleanor R osch and her associates on basiclevel categories. For an overview, see R osch's 'Principles of Categorization' in E. R osch and B. B. L loyd (eds.) C ognition and C ategorization (H illsdale, N J.: Erblaum, 1978). A concise summary of key ideas is given in U Irich $\mathrm{N}$ eisser 'From Direct Perception to Conceptual Structure' in UIrich $\mathrm{N}$ eisser (ed.) C oncepts and C onceptual D evelopment (C ambridge U niversity Press, 1987).

${ }^{21}$ Relevant data are summarised in R. J. Herrnstein, 'Objects, C ategories, and D iscriminative Stimuli' in H . L . R oitblat, T. G. Bever, and H. S. Terrace (eds.) A nimal Cognition (Hillsdale, N J.: Erlbaum, 1984), 233-61 


\section{Alan Millar}

in the formation of beliefs and judgments. ${ }^{22} \mathrm{~T}$ o be warranted in ascribing to the pigeon a belief that an object is a slide of a tree we would have to be able to impute to it some understanding (some conception) of what slides of trees are. There is no need to do so to make sense of the pigeon's behaviour. T he import of the claim that it discriminates slides of trees is simply that it differentiates slides of trees from slides not of trees, in that it responds in a certain way to the slides in the former class and does not respond in that way to slides in the latter class. $\mathrm{N}$ ow, it is possible for someone to be able visually to discriminate things having the look of apples, in the sense just explained, without bringing these things under the concept of things having the look of an apple, or any other concept which might be used to specify how apples look. All that is required is that the person should respond differentially to perceived things which have the look of apples. Suppose now that the differential response is believing ( non-inferentially) that the thing perceived is an apple. Then the discriminative capacity in question is a capacity to believe of perceived things having the look of an apple, that they are apples. I t is a conceptual capacity, because the differential activity is that of bringing the discriminated objects under the concept of an apple, but it need not involve bringing these things under concepts pertaining just to appearances. The proposal, then, so far as visual knowledge is concerned, is that to tell perceptually that something is an $\mathrm{F}$ from the way it looks involves judging that it is an $\mathrm{F}$ by way exercising a capacity for discriminating things having the look of $\mathrm{F} \mathrm{s}$. T here is no need to suppose that the subject who can tell by the look of something that it is an apple must have inferred that it is an apple from a prior assumption as to how it looks.

This proposal gives us a way of reconciling the intuition that what is perceptually manifest, in the strict sense, is fundamental for perceptual knowledge, with the intuition shared by non-inferentialists, that more can be perceived (and thus non-inferentially known) to be so than can be perceptually manifest in that sense. T he question which now arises is whether the resulting theory is more restrictive about the scope of perceptual knowledge than the noninferential approach. If my treatment of the sub-atomic particle

${ }^{22}$ As Peter $\mathrm{C}$ arruthers notes, in $\mathrm{H}$ uman $\mathrm{K}$ nowledge and $\mathrm{H}$ uman $\mathrm{N}$ ature (Oxford U niversity Press, 1992), 95, in one sense in which theorist might use the term 'concept', to have a capacity for discriminating triangles would entail having a concept of a triangle. Carruthers doubts that concepts in this sense figure in beliefs and judgments. I prefer not to treat a creature who can discriminate triangles as having a concept of a triangle unless its differential response to triangles involves a capacity to form beliefs to the effect that the discriminated objects are triangles. 
case is along the right lines then it is more restrictive. $T$ he particle is not seen because there is no way in which it, rather than the effect it produces, looks. A forti ori, we do not have perceptual knowledge that a particle is passing through. What about the other cases? $\mathrm{H}$ ere I confine myself to a few brief remarks.

We need first to take note of an implication of the view I am defending: if one knows perceptually that $A$ is an $F$ from the way it appears, relative to some sense, then A must have an appearance relative to that sense which is (nearly enough) distinctive of $F \mathrm{~s}$ in that most things which have that appearance are F s. T his is required for perceptual discrimination to be possible; only if there are ways of appearing that are (nearly enough) distinctive of $\mathrm{Fs}$ is it possible reliably to form true beliefs or judgments that a thing is an $F$ from its appearance. It is not required that $F$ s have a (nearly enough) characteristic appearance, where that means an appearance that most $\mathrm{F} \mathrm{s}$ have. For the claim is not that usually when an $\mathrm{F}$ is present one can tell that it is an $\mathrm{F}$ from its appearance, but only that it is sometimes possible to tell that something is an $\mathrm{F}$ from its appearance.

I have already sided with $\mathrm{M} \mathrm{CD}$ owell in accepting that there are psychological conditions such that one can sometimes have perceptual knowledge that a person is in such a condition from the way that person appears. The view I have defended gives us a way of making sense of this. W hat is required for us to be able to tell that someone is expressing anxiety from the way he looks is that there should be looks which are (nearly enough) distinctive of expressions of anxiety. It is plausible that this condition is met since it is plausible that there are demeanours which, in suitable contexts, are (nearly enough) distinctive of expressions of anxiety. ( $\mathrm{N}$ ote that such knowledge unproblematically satisfies the perceived-object condition, since it is knowledge regarding the person who expresses anxiety, not knowledge regarding an invisible entity which is the possessor of anxiety.) I t looks plausible, too, that we can have perceptual knowledge of what people say, from the ways they sound, because there are ways of sounding which in suitable contexts are (nearly enough) distinctive of the sayings in question.

W hat of the moral cases? Some of these seem to go the other way. This is true for thin moral concepts like those of right and wrong. I t is not generally true that right and wrong actions have distinctive appearances relative to sight or any other sense. H owever, the kinds of cases which interest M CD owell need more careful consideration, and certainly a fuller treatment than I can give here. T hese are cases in which the kind person makes judgments to the effect that a certain situation calls for some specified action. Suppose that the situation is someone's turning up at one's door late at night and in great 


\section{Alan Millar}

distress. Suppose that the action which we are to imagine that the kind person sees to be required is that of helping to cal $m$ the person down. If my story is right it will be true that the kind person sees that this action is required only if it is true that she sees it is required from the way the situation looks. $\mathrm{N}$ ow it is true that situations of this sort-a person in evident distress and calling on you for help-can be remarkably diverse with respect to the way they look. But that is not to the point. What is required is not that the situations in question should have a characteristic appearance, but that the actual situation should have an appearance which is distinctive of situations which call for the specified action (so that, as a matter of contingent fact, most situations which have the appearance in question are ones which call for the specified action). $\mathrm{N}$ ow it is not altogether implausible to suppose that this condition is actually met-that as a matter of contingent fact most situations which looked like the actual situation would be ones which called for the action in question, if the actual situation called for such action. So it is at least not obvious that making appearances fundamental to perceptual knowledge, even under the restrictive conception of appearances which I have outlined, rules out the possibility of perceptual moral knowledge. For all I have said there might be other considerations (such as $\mathrm{H}$ arman's on support by evidence) which do rule out such a possibility, but I shall not discuss these here. $\mathrm{M}$ y main concern has been to spell out some plausible general constraints on perceptual knowledge, which are relevant to deciding what does or does not fall within the scope of what can be known perceptually, not to defend the possibility of moral knowledge.

U niversity of Stirling 